\title{
BMJ Open Are patients with cancer with sepsis and bacteraemia at a higher risk of mortality? A retrospective chart review of patients presenting to a tertiary care centre in Lebanon
}

\author{
Gilbert Abou Dagher, Christopher El Khuri, Ahel Al-Hajj Chehadeh, Ali Chami, \\ Rana Bachir, Dina Zebian, Ralphe Bou Chebl
}

To cite: Abou Dagher G, El Khuri C, Chehadeh AA-H, et al. Are patients with cancer with sepsis and bacteraemia at a higher risk of mortality? A retrospective chart review of patients presenting to a tertiary care centre in Lebanon. BMJ Open 2017;7 e013502. doi:10.1136/ bmjopen-2016-013502

- Prepublication history for this paper is available online. To view these files please visit the journal online (http://dx.doi.org/10.1136/ bmjopen-2016-013502).

Received 20 July 2016 Revised 2 November 2016 Accepted 24 January 2017

CrossMark

Department of Emergency Medicine, American University of Beirut Medical Center, Beirut, Lebanon

Correspondence to Dr Ralph Bou Chebl; rb94@aub.edu.Ib

\section{ABSTRACT}

Objective: Most sepsis studies have looked at the general population. The aim of this study is to report on the characteristics, treatment and hospital mortality of patients with cancer diagnosed with sepsis or septic shock.

Setting: A single-centre retrospective study at a tertiary care centre looking at patients with cancer who presented to our tertiary hospital with sepsis, septic shock or bacteraemia between 2010 and 2015.

Participants: 176 patients with cancer were compared with 176 cancer-free controls.

Primary and secondary outcomes: The primary outcome of this study was the in hospital mortality in both cohorts. Secondary outcomes included patient demographics, emergency department (ED) vital signs and parameters of resuscitation along with laboratory work.

Results: A total of 352 patients were analysed. The mean age at presentation for the cancer group was $65.39 \pm 15.04$ years, whereas the mean age for the control group was $74.68 \pm 14.04$ years $(p<0.001)$. In the cancer cohort the respiratory system was the most common site of infection $(37.5 \%)$ followed by the urinary system $(26.7 \%)$, while in the cancer-free arm, the urinary system was the most common site of infection (40.9\%). intravenous fluid replacement for the first 24 hours was higher in the cancer cohort. ED, intensive care unit and general practice unit length of stay were comparable in both the groups. $95(54 \%)$ patients with cancer died compared with $75(42.6 \%)$ in the cancer-free group. The 28-day hospital mortality in the cancer cohort was $87(49.4 \%)$ vs $46(26.1 \%)$ in the cancer-free cohort $(p=0.009)$. Patients with cancer had a 2.320 (CI 95\% 1.225 to $4.395, p=0.010$ ) odds of dying compared with patients without cancer in the setting of sepsis.

Conclusions: This is the first study looking at an indepth analysis of sepsis in the specific oncology population. Despite aggressive care, patients with cancer have higher hospital mortality than their cancerfree counterparts while adjusting for all other variables.

\section{Strengths and limitations of this study}

- First study looking at the toll of sepsis in the high-risk oncological population.

- 176 patients with cancer with sepsis were compared with 176 patients with non-oncological sepsis. Both cohorts were similar in terms of demographics.

- Multivariate analysis conducted to minimise confounding bias.

- A retrospective chart review cohort study, and is subjected to bias.

- Single-centre study with a referral tertiary emergency department that deals with regional complicated cases, therefore the applicability of the results would be affected.

\section{INTRODUCTION}

Sepsis is one of the leading and most lethal medical emergencies, with a mortality rate reaching $25 \% .^{1}$ In the USA, sepsis is responsible for $9 \%$ of all cancer-related deaths. ${ }^{2}$ When compared with the non-oncological population, patients with cancer presenting with sepsis or septic shock are more likely to be hospitalised and have worse outcomes. ${ }^{3} 4$ The higher sepsis risk in patients with cancer, terminal or otherwise, is probably due to their state of immunosuppression, often due to the disease burden itself and to the effects of chemotherapy. ${ }^{4}$ There are no studies that looked at the emergency department's (ED) management of oncological patients, their in-hospital mortality from sepsis or septic shock, or the value of the systemic inflammatory response syndrome (SIRS) criteria in this subset of population. Therefore, the rationale behind this study is to evaluate sepsis outcomes in the oncological population compared with the 
cancer-free population presenting to the ED with sepsis or septic shock; and to report on their hospital, 72-hour, and 28-day mortality as primary outcomes, as well as to report the differences in ED management, microbiology and parameters of resuscitation.

\section{METHODS}

\section{Study design and patient selection}

This was an Institutional Review Board approved (IRB\# GA.ER.05), single-centre, retrospective, chart review, cohort study. All patients presenting to the ED of a tertiary care hospital between July 2010 and April 2015 were retrieved from the hospital's electronic health records. Inclusion criteria were a final diagnosis of sepsis, septic shock or bacteraemia. Sepsis and septic shock were defined according to the Surviving Sepsis Campaign guidelines. ${ }^{5}$ Sepsis was defined as having a documented/presumed infection with two or more of the following: temperature $>38$ or $<36{ }^{\circ} \mathrm{C}$, heart rate (HR) of $>90 \mathrm{bpm}$, respiratory rate of $>20$ breaths $/ \mathrm{min}$ or arterial carbon dioxide tension $<32 \mathrm{~mm} \mathrm{Hg}$, white cell count $>12 \times 10^{9}$ cells $/ \mathrm{L}$ or $>10 \%$ bands. Septic shock was defined as having sepsis with any of the following: systolic blood pressure (SBP) $<90 \mathrm{~mm} \mathrm{Hg}$ or mean arterial pressure $<65 \mathrm{~mm} \mathrm{Hg}$ or lactate $>2 \mathrm{mmol} / \mathrm{L}$ after an initial fluid challenge. Bacteraemia was defined as two positive blood culture bottles with skin flora pathogens or one positive blood culture bottle with non-skin flora pathogens. The exclusion criteria were incomplete charts, patients younger than 18 years of age, pregnant or presenting secondary to trauma.

During the selected study period 1017 patients were identified as per our study criteria. Of those, 176 $(17.3 \%)$ had an active solid or haematological malignancy, defined as currently receiving chemotherapy and/or radiation therapy, and were considered as the positive risk factor group in the cohort study. Of the 841 patients who were cancer free, 176 were selected using computer software for random number generation with the intent of producing demographic comparability between the two groups.

The medical records of the chosen oncological and non-oncological septic or septic shock patients were used to retrieve the patients' age, gender, history of comorbidities, type of cancer and history of bone marrow transplantation (BMT). Patients' vital signs and laboratory results were collected at initial presentation to the ED. Causative microorganisms and presence of bacteraemia were retrieved, as well as time to antibiotics, and amount of fluid resuscitation within the first 6 and 24 hours. Duration and type of vasopressors and steroids administration, as well as antibiotic type were collected to determine the appropriateness of antibiotic choice. Appropriate use of antibiotics was defined as a broadspectrum antibiotics regimen covering Gram-positive and Gram-negative bacteria including pseudomonas and anaerobic bacteria. Furthermore, disposition from the $\mathrm{ED}$, length of stay in the ED, intensive care unit (ICU) or general practice unit (GPU), in addition to hospital, 72-hour and 28-day mortality were noted.

\section{Statistical analysis}

A two-tailed sample t-test was used to compare the differences in age, lengths of stay, time to and duration of vasoactive agent therapy, antibiotic and steroid therapy, fluid administration at 6 and 24 hours, vital signs at presentation, as well as electrolytes and blood work between oncological and non-oncological patients. Pearson's $\chi^{2}$ test was used to compare the difference in distribution of bacteraemia, comorbidities, microbiology, use and appropriateness of antibiotics, disposition from the ED, use of vasopressor therapy, use of steroids, lactate level, and hospital, 72-hour and 28-day mortality between the same groups stated above. Statistical analyses were performed using SPSS Statistics for Windows V.21.0. (Armonk, New York, USA: IBM Corp).

In the bivariate analysis, Student's t-test and Pearson's $\chi^{2}$ test were used to assess the significance of the statistical association between the independent variables (continuous and categorical) and hospital mortality; the dependent variable. Both tests were interpreted at a predetermined significance level $(\alpha=0.05)$. Furthermore, the magnitude of association between the predictor variables and hospital mortality was determined through calculating the ORs and their corresponding 95\% CIs. A multivariate analysis was performed using logistic regression to find the best model that fits the data and that explains the association between the two groups in terms of the outcome variable and all predictor factors. A backward selection procedure, with significance level for removal from the model set at 0.1 , was conducted by fitting hospital mortality with all risk factors found to be significant in the bivariate level, in addition to those considered clinically meaningful (age, gender, medical history (diabetes mellitus (DM), coronary artery disease (CAD), hypertension (HTN), cerebrovascular accident (CVA), chronic kidney disease (CKD) on haemodialysis (HD), and systolic heart failure (HF), time to antibiotics, SBP, HR, blood urea nitrogen (BUN), and oncology status)).

\section{RESULTS}

\section{Total cohort and oncological cohort characteristics}

The mean age at presentation for the cancer group was $65.39 \pm 15.05$ years, with the mean age for the control group being $74.68 \pm 14.04$ years $(p<0.001)$. There was a higher number of male patients in the oncological arm $(63.6 \%)$ than in the non-oncological arm $(51.7 \%)$. The diagnosis of septic shock in both groups was statistically similar. Furthermore, there was a higher percentage of patients with HTN ( $71 \%$ vs $53.4 \%)$, diabetes $(44.3 \%$ vs $30.1 \%)$, CAD (44.3\% vs $23.3 \%$ ) and non-systolic HF (29\% vs $19.3 \%)$ in the non-oncological arm compared with the oncological arm. In terms of infection characteristics, both groups were similar regarding the 
Table 1 Patient demographic characteristics

\begin{tabular}{|c|c|c|c|}
\hline & $\begin{array}{l}\text { Oncological } \\
(\mathrm{N}=176)\end{array}$ & $\begin{array}{l}\text { Non-oncological } \\
(\mathrm{N}=176)\end{array}$ & p Value \\
\hline Age (years) (mean $\pm S D)$ & $65.39 \pm 15.046$ & $74.68 \pm 14.044$ & $<0.001$ \\
\hline Male sex $n(\%)$ & $112(63.6)$ & $91(51.7)$ & 0.023 \\
\hline \multicolumn{4}{|l|}{ Diagnosis n (\%) } \\
\hline Septic shock & 109 (61.9) & $101(57.4)$ & 0.385 \\
\hline Sepsis & $67(38.1)$ & 75 (42.6) & \\
\hline HTN n (\%) & $94(53.4)$ & $125(71.0)$ & 0.001 \\
\hline DM n (\%) & $53(30.1)$ & $78(44.3)$ & 0.006 \\
\hline CAD n (\%) & $41(23.3)$ & 78 (44.3) & $<0.001$ \\
\hline Non-systolic CHF: EF $\geq 40 \%$ n (\%) & 34 (19.3) & $51(29.0)$ & 0.034 \\
\hline Systolic CHF: EF<40\% n (\%) & $25(14.2)$ & $34(19.3)$ & 0.199 \\
\hline COPD/emphysema n (\%) & $24(13.6)$ & $27(15.3)$ & 0.650 \\
\hline CKD on HD n (\%) & $9(5.1)$ & $23(13.1)$ & 0.009 \\
\hline CVA n (\%) & $8(4.5)$ & $37(21.0)$ & $<0.001$ \\
\hline Bacteraemia n (\%) & $66(37.5)$ & $63(35.7)$ & 0.740 \\
\hline Site of infection $\mathrm{n}(\%)$ & & & $<0.001$ \\
\hline Lung & $66(37.5)$ & $67(38.1)$ & \\
\hline Gastrointestinal & $23(13.1)$ & $12(6.8)$ & \\
\hline Urine & $47(26.7)$ & $72(40.9)$ & \\
\hline Skin & $5(2.8)$ & $13(7.4)$ & \\
\hline Oral cavity & $1(0.6)$ & $0(0.0)$ & \\
\hline Catheter & $4(2.3)$ & $4(2.3)$ & \\
\hline Bile & $5(2.8)$ & $4(2.3)$ & \\
\hline Liver & $1(0.6)$ & $1(0.6)$ & \\
\hline Undetermined & $24(13.6)$ & $3(1.7)$ & \\
\hline \multicolumn{4}{|l|}{ Microbiology isolates } \\
\hline CoNS* & $13(7.4)$ & $11(6.3)$ & 0.672 \\
\hline Staphylococcus aureus & $9(5.1)$ & $6(3.4)$ & 0.429 \\
\hline Escherichia coli & $60(34.1)$ & $77(43.8)$ & 0.063 \\
\hline Klebsiella pneumonia & $23(13.1)$ & $12(6.8)$ & 0.050 \\
\hline Pseudomonas aeruginosa & $12(6.8)$ & $16(9.1)$ & 0.431 \\
\hline Acinetobacter baumani & $8(4.5)$ & $11(6.3)$ & 0.479 \\
\hline Enterococcus spp. & $7(4.0)$ & $7(4.0)$ & 1.000 \\
\hline Proteus mirabilis & $4(2.3)$ & $9(5.1)$ & 0.158 \\
\hline Streptococcus spp. & $7(4.0)$ & $12(6.8)$ & 0.238 \\
\hline Clostridium spp. & $3(1.7)$ & $1(0.6)$ & 0.312 \\
\hline Otherst & $22(12.5)$ & $17(9.7)$ & 0.396 \\
\hline
\end{tabular}

percentage of bacteraemic patients $(37.5 \%$ vs $35.7 \%$, $\mathrm{p}=0.704)$. In the cancer cohort, the respiratory system was the most common site of infection $(37.5 \%)$, followed by the urinary system $(26.7 \%)$ and the gastrointestinal system $(13.1 \%)$. In the cancer-free arm, the urinary system was the most common site of infection $(40.9 \%)$, followed by the respiratory system $(38.1 \%)$ and the integumentary system $(7.4 \%)$. The site of infection was not identified in $13.6 \%$ of patients with cancer compared with only $1.7 \%$ of patients who were cancer free. With regard to microbiology isolates, both groups were comparable with Escherichia coli being the most prevalent in both groups. The information presented is summarised in table 1 .
The oncological cohort, as shown in table 2, was comprised of $19.9 \%$ haematological tumours and $80.1 \%$ solid tumours. Lung cancer (18\%) was the most prevalent type of cancer, followed by acute and chronic leukaemia $(11.9 \%)$, and breast cancer $(11.4 \%)$. In terms of therapy, $22.8 \%$ of the haematological patients underwent BMT previously, and out of the total cancer cohort, $83.5 \%$ recently underwent chemotherapy and $35.2 \%$ received radiation therapy. When hospital, 72-hour and 28-day mortality analysis was conducted for the patients who underwent BMT compared with those who did not, no differences were noted between the two subgroups. Similar analysis was performed between haematological tumours and solid tumours, and likewise, no significant mortality difference was noted. 
Table 2 Type of malignancy and treatments in the oncological cohort

\begin{tabular}{lc}
\hline & $\begin{array}{c}\text { Oncology } \\
\text { patients } \\
\text { N=176 }\end{array}$ \\
\hline Total haematological tumours n (\%) & $35(19.9)$ \\
Leukaemia* & $20(10.9)$ \\
Lymphoma & $13(7.1)$ \\
Multiple myeloma & $2(1.1)$ \\
Underwent BMT† & $8(22.8) \dagger$ \\
Total solid tumours $n$ (\%) & $141(80.1)$ \\
Lung cancer & $32(17.5)$ \\
Breast cancer & $20(10.9)$ \\
Pancreatic cancer & $14(7.7)$ \\
Bladder cancer & $13(7.1)$ \\
Prostate cancer & $12(6.6)$ \\
Ovarian cancer & $8(4.4)$ \\
Colon cancer & $8(4.4)$ \\
Cholangiocarcinoma & $8(4.4)$ \\
Liver cancer & $7(3.8)$ \\
Rectal cancer & $6(3.3)$ \\
Laryngeal cancer & $4(2.2)$ \\
Otherł & $16(8.7)$ \\
Current chemotherapy regiment $n$ (\%) & $147(83.5)$ \\
Current radiation therapy $n$ (\%) & $62(35.2)$ \\
\hline *Includes acute and chronic leukaemia. & \\
†Percentage is out of the total of haematological malignancy \\
patients (ie, N=35). \\
¥Gastric, kidney, thyroid, brain, oesophageal, sarcoma, \\
nasopharyngeal, thymus and anal cancer. \\
BMT, bone marrow transplantation. \\
\end{tabular}

Vital signs and laboratory studies on ED presentation

Compared with the cancer-free group, patients with cancer had a significantly lower average SBP (99.64 vs $110.33 \mathrm{~mm} \mathrm{Hg}$, respectively, $\mathrm{p}<0.001$ ), and a significantly higher HR at presentation to the ED (110.32 vs $98.48 \mathrm{bpm}, \mathrm{p}<0.001)$. Moreover, $38.1 \%$ of the patients with cancer had a SBP at presentation lower than $90 \mathrm{~mm} \mathrm{Hg}$ compared with $23.6 \%$ in the cancer-free arm. With respect to laboratory studies, notably lactic acid levels at presentation to the ED (drawn on 102 patients with cancer and 100 of the patients who were cancer free) were slightly higher in the cancer cohort as compared with the control group (4.37 vs $3.80 \mathrm{mg} / \mathrm{dL}$ ). In the cancer arm, $44.1 \%$ of patients had a lactate level above $4 \mathrm{mg} / \mathrm{dL}$, compared with $26 \%$ in the control group $(p=0.007)$. Furthermore, there was a significant difference in the average haemoglobin levels between patients with cancer and patients who were cancer free ( $10.1 \mathrm{vs} 11.4 \mathrm{~g} / \mathrm{dL}$, respectively, $\mathrm{p}<0.001)$. These findings are summarised in table 3 .

\section{Sepsis treatment variables and patients' length of stay}

Patients with cancer required more fluids, with the cancer cohort receiving at 6 hours an average of $3.34 \mathrm{~L}$ compared with $2.69 \mathrm{~L}$ in the cancer-free group ( $p=0.003$ ) and at 24 hours, $6.24 \mathrm{~L}$ compared with $5 \mathrm{~L}$ in the cancer-free group $(\mathrm{p}<0.001)$. Regarding vasopressor use, a total of $51.7 \%$ of patients with cancer required vasopressors at one point during their hospital admission compared with only $39.2 \%$ of the patients who were

Table 3 Vital signs and laboratory parameters on presentation to the ED

\begin{tabular}{|c|c|c|c|}
\hline & $\begin{array}{l}\text { Oncological } \\
(\mathrm{N}=176)\end{array}$ & $\begin{array}{l}\text { Non-oncological } \\
(\mathrm{N}=176)\end{array}$ & p Value \\
\hline $\mathrm{SBP}(\mathrm{mm} \mathrm{Hg})(\operatorname{mean} \pm \mathrm{SD})$ & $99.6 \pm 23.4$ & $110.3 \pm 26.6$ & $<0.001$ \\
\hline $\mathrm{DBP}(\mathrm{mm} \mathrm{Hg})($ mean $\pm \mathrm{SD})$ & $57.1 \pm 15.3$ & $60.3 \pm 18.0$ & 0.069 \\
\hline MAP $(m m ~ H g) ~(m e a n \pm S D)$ & $71.3 \pm 16.5$ & $76.8 \pm 19.1$ & 0.002 \\
\hline $\mathrm{HR}(\mathrm{bpm})($ mean $\pm \mathrm{SD})$ & $110.3 \pm 24.9$ & $98.3 \pm 23.2$ & $<0.001$ \\
\hline $\mathrm{O}_{2}$ saturation $(\%)($ mean $\pm \mathrm{SD})$ & $93.8 \pm 8.2$ & $93.4 \pm 6.7$ & 0.570 \\
\hline Temperature $\left({ }^{\circ} \mathrm{C}\right)($ mean $\pm \mathrm{SD})$ & $37.2 \pm 1.1$ & $37.6 \pm 1.2$ & 0.004 \\
\hline RR (breaths/min) (mean $\pm S D)$ & $23.5 \pm 7.2$ & $23.4 \pm 6.8$ & 0.889 \\
\hline Glucose (mg/dL) (mean $\pm S D)$ & $154.2 \pm 81.5$ & $166.5 \pm 103.3$ & 0.249 \\
\hline Lactate $(\mathrm{mmol} / \mathrm{L})(\mathrm{mean} \pm \mathrm{SD})$ & $4.37 \pm 3.27$ & $3.80 \pm 3.69$ & 0.252 \\
\hline WCC $\left(\times 10^{9}\right.$ cells $\left./ L\right)($ mean $\pm S D)$ & $14.28 \pm 16.62$ & $15.10 \pm 8.76$ & 0.565 \\
\hline Haemoglobin (g/dL) (mean $\pm S D)$ & $10.07 \pm 2.11$ & $11.42 \pm 2.05$ & $<0.001$ \\
\hline Haematocrit (\%) (mean \pm SD) & $29.98 \pm 6.46$ & $34.14 \pm 6.13$ & $<0.001$ \\
\hline Bicarbonate $(\mathrm{mmol} / \mathrm{L})(\operatorname{mean} \pm \mathrm{SD})$ & $19.80 \pm 5.64$ & $20.36 \pm 6.05$ & 0.370 \\
\hline BUN (mg/dL) (mean $\pm S D)$ & $38.43 \pm 24.52$ & $49.17 \pm 35.69$ & 0.001 \\
\hline Creatinine $(\mathrm{mg} / \mathrm{dL})($ mean $\pm \mathrm{SD})$ & $1.75 \pm 1.54$ & $2.26 \pm 1.79$ & 0.004 \\
\hline Arterial $\mathrm{pH}($ mean $\pm \mathrm{SD})$ & $7.35 \pm 0.11$ & $7.35 \pm 0.12$ & 0.704 \\
\hline INR (mean+SD) & $1.71 \pm 1.06$ & $1.93 \pm 1.41$ & 0.192 \\
\hline \multicolumn{4}{|l|}{ Lactate* $^{\star}$} \\
\hline$\geq 4(\mathrm{mmol} / \mathrm{L})(\%)$ & $44.1 \%$ & $26.0 \%$ & 0.007 \\
\hline
\end{tabular}


cancer free. Of the cancer cohort, $44.3 \%$ of patients required vasopressor therapy in the first 24 hours, compared with $34.7 \%$ of patients from the control group. Antibiotics were administered after an average of 4.73 hours in the patients with cancer and 2.77 hours in the control patients, with the majority of patients in both groups receiving their antibiotics in the ED $(93.2 \%$ and $92 \%$, respectively). Of note, both groups had similar ED, ICU and GPU length of stays. Table 4 summarises the differences in the ED management between the two arms of the study.

\section{Patient mortality and hospital mortality logistic regression}

During their hospital stay, a total of $96(54 \%)$ patients with cancer died compared with $75(42.6 \%)$ patients in the cancer-free group $(\mathrm{p}=0.033)$. The 72 -hour mortality was higher in the cancer group, as $26(14.7 \%)$ of the patients with cancer died compared with only $11(6.3 \%)$ of the control patients $(p=0.009)$. Furthermore, patients with cancer had a significantly higher 28-day mortality compared with control patients $(49.4 \%$ vs $26.1 \%$ respectively, $\mathrm{p}<0.001$ ).

Table 5 shows the logistic regression done, with hospital mortality as the dependent variable, to determine the major predictors of this primary outcome. Age, sex, comorbidities (DM, CAD, HTN, CVA, CKD on HD, and
$\mathrm{HF}$ ), previous use of steroids, time to antibiotic initiation, SBP and HR on presentation along with BUN were chosen as factors to be controlled for, due to their clinical meaningfulness and statistical difference between oncological and non-oncological patients. The multivariate analysis showed statistical significance only for being an oncological patient as a predictor of hospital mortality. While adjusting for all other variables, oncological patients had 2.32 higher odds of hospital mortality than their cancer-free counterparts in the setting of either sepsis or septic shock.

\section{DISCUSSION}

In 2001, the Early Goal Directed Therapy (EGDT) protocol, by Rivers et at was the first major study that tackled sepsis-related mortality and led to a shift towards a protocol-based, more aggressive sepsis care in the ED. Recent published data have advocated for earlier recognition of sepsis, with an early emphasis on fluid resuscitation and antibiotic administration. ${ }^{7-9}$ The majority of sepsis studies, however, have looked at the general population and neglected to look at high-risk patient populations such as the oncological patients. ${ }^{10-13}$ The aim of this study was to look at patients with cancer who presented to the ED with sepsis or septic shock and to compare them to patients who were cancer free with a

Table 4 Sepsis treatment variables and patients' LOS

\begin{tabular}{|c|c|c|c|}
\hline & $\begin{array}{l}\text { Oncological } \\
(\mathrm{N}=176)\end{array}$ & $\begin{array}{l}\text { Non-oncological } \\
(\mathrm{N}=176)\end{array}$ & $\begin{array}{l}p \\
\text { Value }\end{array}$ \\
\hline IV fluid requirement in first 6 hours $(L)($ mean $\pm S D)$ & $3.34 \pm 2.17$ & $2.69 \pm 1.87$ & 0.003 \\
\hline IV fluid requirement in first 24 hours $(\mathrm{L})($ mean \pm SD) & $6.24 \pm 3.11$ & $5.00 \pm 2.59$ & $<0.001$ \\
\hline Vasopressor use: levophed (\%) & $51.7 \%$ & $39.2 \%$ & 0.019 \\
\hline Vasopressor use: dopamine (\%) & $6.8 \%$ & $10.2 \%$ & 0.252 \\
\hline Inotrope use: dobutamine (\%) & $0.6 \%$ & $2.8 \%$ & 0.100 \\
\hline Vasopressor/inotrope use within the first 24 hours (\%) & $44.3 \%$ & $34.7 \%$ & 0.064 \\
\hline Time to vasopressor/inotrope use within first 24 hours (hours) (mean \pm SD) & $7.03 \pm 5.72$ & $6.77 \pm 5.84$ & 0.792 \\
\hline $\begin{array}{l}\text { Vasopressors/inotrope treatment duration within first } 24 \text { hours (hours) } \\
\text { (mean } \pm \text { SD) }\end{array}$ & $15.73 \pm 6.39$ & $16.02 \pm 6.85$ & 0.801 \\
\hline Steroid use (\%) & $32.4 \%$ & $29.0 \%$ & 0.488 \\
\hline Antibiotics use* (\%) & $99.4 \%$ & $98.9 \%$ & 0.562 \\
\hline Appropriate antibiotic $\ddagger(\%)$ & $92.1 \%$ & $92.2 \%$ & 0.979 \\
\hline Antibiotics initiated in ED (\%) & $93.2 \%$ & $92.0 \%$ & 0.684 \\
\hline Antibiotics initiated in ICU (\%) & $1.1 \%$ & $1.7 \%$ & 0.652 \\
\hline Antibiotics initiated in GPU (\%) & $5.1 \%$ & $5.7 \%$ & 0.814 \\
\hline Time to initiation of antibiotics (hours) (mean \pm SD) & $4.73 \pm 12.71$ & $2.77 \pm 2.70$ & 0.047 \\
\hline ED LOS (hours) (mean \pm SD) & $23.07 \pm 38.48$ & $23.48 \pm 35.84$ & 0.917 \\
\hline ICU LOS (days) (mean \pm SD) & $10.16 \pm 12.55$ & $14.93 \pm 30.31$ & 0.184 \\
\hline GPU LOS (days) (mean \pm SD) & $9.40 \pm 10.07$ & $9.88 \pm 13.39$ & 0.798 \\
\hline Hospital LOS (days)§ (mean \pm SD) & $15.43 \pm 17.41$ & $16.45 \pm 29.71$ & 0.790 \\
\hline \multicolumn{4}{|c|}{$\begin{array}{l}\text { *Variable was calculated for patients who are bacteraemic that received antibiotics ( } \mathrm{N}=128 \text {, with } 66 \text { patients with cancer and } 63 \text { patients } \\
\text { without cancer). } \\
\text { †Variable was calculated only for patients who are bacteraemic that received antibiotics, and had an available bacterial sensitivity ( } \mathrm{N}=127, \\
\text { with } 65 \text { patients with cancer and } 63 \text { patients without cancer). } \\
\text { †Appropriate use of antibiotics was defined as a broad-spectrum antibiotics regimen covering Gram-positive, Gram-negative bacteria including } \\
\text { pseudomonas and anaerobic bacteria. } \\
\text { §Hospital LOS days were calculated only for those that did not expire in hospital (as shorter LOS times may be associated with early deaths). } \\
\text { ED, emergency department; GPU, general practice unit; ICU, intensive care unit; IV, intravenous; LOS, length of stay. }\end{array}$} \\
\hline
\end{tabular}


Table 5 Multiple logistic regression for hospital mortality

\begin{tabular}{|c|c|c|c|c|c|c|}
\hline & \multirow[b]{2}{*}{$\begin{array}{l}\text { Oncological } \\
(\mathrm{N}=176)\end{array}$} & \multirow[b]{2}{*}{$\begin{array}{l}\text { Non-oncological } \\
(\mathrm{N}=176)\end{array}$} & \multicolumn{2}{|l|}{ Crude* $^{*}$} & \multicolumn{2}{|l|}{ Adjusted $†$} \\
\hline & & & OR (Cl 95\%) & p Value & OR (Cl 95\%) & p Value \\
\hline Hospital mortality $n(\%)$ & $95(54)$ & $75(42.6)$ & 1.579 (1.036 to 2.405$)$ & 0.033 & 2.320 (1.225 to 4.395$)$ & 0.010 \\
\hline
\end{tabular}

similar presentation, with an emphasis on demographics, ED management and mortality.

While there is a paucity of the literature on sepsis in the oncological patients, some researchers have tackled this issue. Angus et $a l^{14}$ showed that one in six patients with severe sepsis have an underlying malignancy. Williams et $a l^{3}$ constructed a database of patients with cancer admitted to the hospital and compared patients with cancer with severe sepsis to patients with non-severe sepsis. They found that patients with cancer with severe sepsis were older, had more comorbid conditions and a higher mortality than patients with cancer without severe sepsis; however, they did not compare patients with cancer to patients who are cancer free. According to our results, patients with septic cancer are younger and have less comorbid conditions than the general population and are more haemodynamically unstable at presentation.

Angus et $a l^{14}$ reported a $30 \%$ increase in mortality in patients with cancer with severe sepsis. Furthermore, Williams $e t a l^{3}$ reported that the overall hospital mortality for patients with severe sepsis with cancer was 52\% higher than that of patients with non-cancer severe sepsis $(37.8 \%$ vs $24.9 \%$, respectively) and was five times greater than the non-severe sepsis cancer hospital mortality. In our study, the in-hospital mortality was higher in the oncological group (54\%) compared with the control group (42.6\%; $\mathrm{p}<0.001)$. Similar to the Angus study, we found that patients with cancer had a $29 \%$ increase in in-hospital mortality, and that an underlying malignancy in a patient with sepsis increased the odds of dying by 2.32 times. This increased risk of death could be explained by the burden the tumour imposes on the host, through the production of cytokines or secondary to localised obstruction, as well as chemotherapy and the ensuing immunosuppressed state that significantly decreases the host's immune system and predisposes the host to opportunistic infections. ${ }^{3} 15$

In their registry of patients, Williams $e t a \vec{l}$ found that the incidence of severe sepsis was higher in haematological tumours than in solid tumours; however, they noted that both cancer types had a similar mortality. This finding of similar haematological/solid tumour mortality is echoed in our study as well. Moreover, they found that lung cancer was associated with the highest mortality. The highest mortality in our cancer cohort was associated with gastrointestinal (GI) infections, which could probably be explained by the tumour obstructing GI structures and acting as a nidus for infection and continuous bacterial seeding. Infections in these sites generally require complex surgical interventions, which may not be possible due to the nature, location and prognosis of the disease. ${ }^{16}$

At the time of this study, there was no sepsis management protocol at our institution. Patients with cancer received on average $3.34 \pm 2.17 \mathrm{~L}$ of fluids at 6 hours, which is in line with the $30 \mathrm{cc} / \mathrm{kg}$ fluid resuscitation guidelines set by the Surviving Sepsis Campaign guidelines. ${ }^{17}$ Broad-spectrum antibiotics were initiated in all cases of sepsis and septic shock with a combination of vancomycin and carbapenems being the most commonly used antibiotics. However, the time to antibiotic administration from presentation was longer than the 3 hours set guideline, with an average of 4.73 \pm 12.72 hours in the oncological cohort as opposed to 2.77 hours in the cancer-free cohort. The delay in antibiotics administration in the cancer cohort could have possibly contributed to our high mortality. ${ }^{18}$ Metersky et $a l^{19}$ found that the main reason for delay of antibiotics in their patient population was an incoherent presentation, such as normal vital signs and non-specific localising symptoms that delayed diagnosis. In our study, the delay could have been due to several reasons; on one hand, the presenting temperature in the cancer cohort was lower than the non-cancer cohort, while on the other hand, the presence of non-infectious acute inflammatory disorders can mimic sepsis in patients with malignancies and confound the clinical picture. For instance, patients with acute monocytic leukaemia often have pulmonary infiltrates. ${ }^{20}$ Furthermore, induction treatments may precipitate tumour lysis syndrome, which may result in multiorgan dysfunction. All of these non-infectious processes might have influenced the clinicians and lead to the delay in diagnosis.

According to the literature, the length of stay of patients with severe sepsis cancer' was almost three times as long as that of the patients with septic cancer and the incurred hospitalisation costs was three times as much. ${ }^{3}$ While we did not conduct a cost analysis, we had very similar lengths of stay between the two cohorts. It is important to note that there is a limited amount of ICU beds at our institution; and very often, patients requiring an ICU admission tend to remain in the ED for an extended period of time. This in part explains our long ED length of stay and our high GPU admission rate.

Finally, the majority of patients in both cohorts presented with two or more SIRS criteria, showing that in accordance with the literature, SIRS criteria have a high sensitivity. ${ }^{21}$ However, there was no correlation between 
the number of SIRS criteria and mortality in either group. Of the patients with cancer who were admitted and were treated for sepsis during their hospital stay, 27 $(15 \%)$ were found to have $<2$ SIRS criteria at presentation, with a total of 13 patients $(48.1 \%)$ dying during their hospital stay. SIRS-negative sepsis has been described in the literature, with the latest studies showing that about $12 \%$ of patients with sepsis have $<2$ SIRS criteria at presentation. ${ }^{414}$ Though it may not fulfil the definition of sepsis, emergency physicians should always be vigilant and have a low threshold to suspect sepsis in patients with cancer given that these patients can present with normal vital signs, deteriorate during their admission and end up with a diagnosis of sepsis.

\section{Limitations}

This was a retrospective chart review cohort study and as such authors are aware of the inherent limitations of such a type of study. To minimise biases from this, frequent meetings were held between the principal investigator and data collectors to standardise the way in which data are collected, entered and cleaned. The increased mortality seen in the oncological cohort could be due to several reasons. First and foremost, the study is from a referral tertiary centre ED that deals with regional complicated cases, which could limit the generalisability of the results to the whole oncological subpopulation. Second, the delay in antibiotic administration in the oncological cohort might have led to the increased mortality. In the analysis stage, the equally numbered groups were found to be unmatched and possibly difficult to compare and conclude meaningful evidence from. In an effort to correct for this, bivariate analysis was performed, and characteristics that were statistically different between the populations along with clinically meaningful elements were controlled for in the multivariate analysis in order to minimise confounding variables. One possible confounding factor not accounted for is oncological patients being diagnosed with terminal cancer, as these patients would have higher mortality rates than other patients with cancer thus limiting our conclusion. According to the literature, the most common definition for terminal illness is an expected 3-month cut-off for survival in addition to inutility of chemotherapy or current regiment in treating the disease. ${ }^{22-24}$ However, in accordance with the local culture and setting of the study, patients are not labelled terminal and services such as hospice care are not available, and patients typically receive chemotherapy until the end of their disease. Resolving all the aforementioned issues poses a problem outside the scope of this article but the authors concede that the mortality might have been falsely elevated given the fact that some patients might have expired from their advanced cancer as well as sepsis.

\section{CONCLUSION}

This study is one of the first studies looking at sepsis and septic shock in the oncological versus the non- oncological population. It shows that in the setting of sepsis or septic shock in the ED, patients with cancer (haematological or solid) have higher hospital mortality than their cancer-free counterparts while adjusting for all other variables. Patients with cancer with sepsis or septic shock, are usually younger and have less comorbidities at presentation, but tend to have a higher mortality despite aggressive care. We hope that this study sheds light on this topic and stimulates further research on sepsis in vulnerable patient population.

Contributors $\mathrm{GAD}$ and $\mathrm{RBC}$ have made substantial contributions to conception and design of the study. AA-HC, AC, RB and DZ were involved in acquisition of data, analysis and interpretation of data. GAD, RBC, CEK and $A A-H C$ have been involved in drafting the manuscript. GAD, RBC and CEK were involved in revising manuscript critically for important intellectual content. All authors contributed substantially to its revision. GAD and RBC take responsibility for the paper as a whole.

Funding This research received no specific grant from any funding agency in the public, commercial or not-for-profit sectors.

Competing interests None declared.

Patient consent Obtained.

Ethics approval Institutional Review Board of the American University of Beirut.

Provenance and peer review Not commissioned; externally peer reviewed.

Data sharing statement Additional data can be accessed via the Dryad data repository at http://datadryad.org/ with the doi:10.5061/dryad.6qk05.

Open Access This is an Open Access article distributed in accordance with the Creative Commons Attribution Non Commercial (CC BY-NC 4.0) license, which permits others to distribute, remix, adapt, build upon this work noncommercially, and license their derivative works on different terms, provided the original work is properly cited and the use is non-commercial. See: http:// creativecommons.org/licenses/by-nc/4.0/

\section{REFERENCES}

1. Jaimes F, Garcés J, Cuervo J, et al. The systemic inflammatory response syndrome (SIRS) to identify infected patients in the emergency room. Intensive Care Med 2003;29:1368-71.

2. Hartnett S. Septic shock in the oncology patient. Cancer Nurs 1989;12:191-201.

3. Williams MD, Braun LA, Cooper LM, et al. Hospitalized cancer patients with severe sepsis: analysis of incidence, mortality, and associated costs of care. Crit Care 2004;8:R291-8.

4. Chanock S. Evolving risk factors for infectious complications of cancer therapy. Hematol Oncol Clin North Am 1993;7: 771-93.

5. Dellinger RP, Levy MM, Rhodes A, et al. Surviving sepsis campaign: international guidelines for management of severe sepsis and septic shock: 2012. Crit Care Med 2013;41:580-637.

6. Rivers E, Nguyen B, Havstad S, et al. Early goal-directed therapy in the treatment of severe sepsis and septic shock. N Engl J Med 2001;345:1368-77.

7. Peake SL, Delaney A, Bailey M, et al., ARISE Investigators; ANZICS Clinical Trials Group. Goal-directed resuscitation for patients with early septic shock. N Engl J Med 2014;371: 1496-506.

8. Yealy DM, Kellum JA, Huang DT, et al., ProCESS Investigators. A randomized trial of protocol-based care for early septic shock. N Engl J Med 2014;370:1683-93.

9. Mouncey PR, Osborn TM, Power GS, et al. Trial of early, goal-directed resuscitation for septic shock. N Engl J Med 2015;372:1301-11.

10. Linde-Zwirble WT, Angus DC. Severe sepsis epidemiology: sampling, selection, and society. Crit Care 2004;8:222-6.

11. Wang HE, Shapiro NI, Angus DC, et al. National estimates of severe sepsis in United States emergency departments. Crit Care Med 2007;35:1928-36. 
12. Gaieski DF, Edwards JM, Kallan MJ, et al. Benchmarking the incidence and mortality of severe sepsis in the United States. Crit Care Med 2013;41:1167-74.

13. Martin GS, Mannino DM, Eaton S, et al. The epidemiology of sepsis in the United States from 1979 through 2000. N Engl J Med 2003;348:1546-54.

14. Angus DC, Linde-Zwirble WT, Lidicker J, et al. Epidemiology of severe sepsis in the United States: analysis of incidence, outcome, and associated costs of care. Crit Care Med 2001;29:1303-10.

15. Allegretta GJ, Weisman SJ, Altman AJ. Oncologic emergencies II. Hematologic and infectious complications of cancer and cancer treatment. Pediatr Clin North Am 1985:32:613-24.

16. Bosscher MR, van Leeuwen BL, Hoekstra HJ. Mortality in emergency surgical oncology. Ann Surg Oncol 2015;22:1577-84.

17. Levy MM, Dellinger RP, Townsend SR, et al. The Surviving Sepsis Campaign: results of an international guideline-based performance improvement program targeting severe sepsis. Crit Care Med 2010;38:367-74.

18. Gaieski DF, Mikkelsen ME, Band RA, et al. Impact of time to antibiotics on survival in patients with severe sepsis or septic shock in whom early goal-directed therapy was initiated in the emergency department. Crit Care Med 2010;38:1045-53.

19. Metersky ML, Sweeney TA, Getzow MB, et al. Antibiotic timing and diagnostic uncertainty in Medicare patients with pneumonia: is it reasonable to expect all patients to receive antibiotics within 4 hours? Chest 2006;130:16-21.

20. Azoulay E, Canet E, Raffoux E, et al. Dexamethasone in patients with acute lung injury from acute monocytic leukaemia. Eur Respir $J$ 2012;39:648-53.

21. Comstedt P, Storgaard M, Lassen AT. The Systemic Inflammatory Response Syndrome (SIRS) in acutely hospitalised medical patients: a cohort study. Scand J Trauma Resusc Emerg Med 2009;17:67.

22. Kaukonen KM, Bailey M, Pilcher D, et al. Systemic inflammatory response syndrome criteria in defining severe sepsis. N Engl J Med 2015;372:1629-38

23. Viganò $\mathrm{A}$, Dorgan $\mathrm{M}$, Buckingham $\mathrm{J}$, et al. Survival prediction in terminal cancer patients: a systematic review of the medical literature. Palliat Med 2000;14:363-74.

24. Aabom B, Kragstrup J, Vondeling $\mathrm{H}$, et al. Defining cancer patients as being in the terminal phase: who receives a formal diagnosis, and what are the effects? J Clin Oncol 2005;23:7411-16. 